\title{
Glanular Anterior Urethral Valve; A Case Report of an Unusual Cause of Neonatal Urinary Retention
}

\author{
Mohammad Aminu Mohammad \\ Bayero University and Aminu Kano Teaching Hospital, Kano, Nigeria \\ Email: mohammadsurgery@yahoo.com
}

Received 26 April 2016; accepted 5 June 2016; published 9 June 2016

Copyright (c) 2016 by author and Scientific Research Publishing Inc.

This work is licensed under the Creative Commons Attribution International License (CC BY).

http://creativecommons.org/licenses/by/4.0/

(c) () Open Access

\begin{abstract}
Anterior urethral valve is an uncommon abnormality whose etiology is uncertain, unlike in the case of posterior urethral valve. Glanular anterior urethral valve is even rarer. We present an unusual case of anterior urethral valve, which presented with acute urinary retention and was successfully managed with excision and glans reconstruction. A history of poor stream and dribbling, recurrent urinary tract infections and palpable penile or peno-scrotal mass strongly points to the diagnosis of anterior urethral valve. A voiding cystourethrogramme confirms the diagnosis. It can cause early proximal urinary tract damage and renal failure if not intervened in time. Early surgical intervention will prevent the onset of uremia. Transurethral resection is the treatment of choice.
\end{abstract}

\section{Keywords}

\section{Glanular, Anterior Urethral Valve, Urinary Retention}

\section{Introduction}

Urethral valves are congenital anomalies that affect the urethra below the bladder neck commonly seen in boys. Posterior Urethral Valve (PUV) is the most prevalent; these are sail like valves that are found in the posterior urethra just below the verumontanum. Anterior Urethral Valves (AUV) are quite rare [1]-[3]. The recognition and the original report on anterior urethral valves is attributed to Williams in 1958 and, since then, several cases have been described, both separately and in association with proximal urethral diverticula [1] [2]. Association of the two is extremely rare and only four cases have been reported [2].

Anterior urethral valves are more common in the bulbar urethra (40\%) and equally occur in penile urethra and 
penoscrotal junction (30\%). Some cases were described at the navicular fossa, and often mistaken for urethral meatal stenosis [1]. Glanular anterior urethral valves are the least common.

This report describes a case of glanular anterior urethral valve, emphasizing its clinical and therapeutic aspects.

Case report

The child was delivered at 36 weeks of gestation and was immediately noted to have swollen distal part of the penis. He was subsequently noted to have difficulty passing urine which only came in drops. With bulging of glanular urethra, the mother had prenatal ultrasonograpy and no fetal anomaly was reported. This baby presented at the age of 16 days. His chief complains were dribbling of turbid urine, bulging of the distal part of the penis and intermittent high grade fever. He had antibiotic therapy from the first week of life (Figure 1).

Patient was evaluated with ultrasound which showed thickened urinary bladder and moderate hydro ureters with normal renal function. He had catheterization, parenteral antibiotics (oral amoxicillin $50 \mathrm{mg} / \mathrm{kg}$ and later parenteral ceftriaxone $50 \mathrm{mg} / \mathrm{kg}$ ) and had excision of the diverticulum and glanuloplasty. He did well post surgery and repeat renal function assessment remained normal with adequate urinary stream. At three month of post excision, there was no episode urosepsis or lower urinary tract symptoms (Figure 2 and Figure 3).

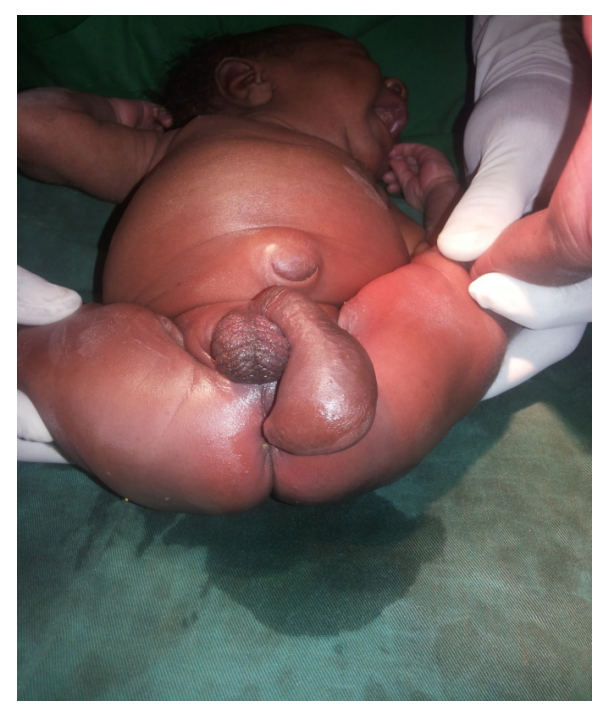

Figure 1. Anterior urethral valve showing bulging glanular urethra.

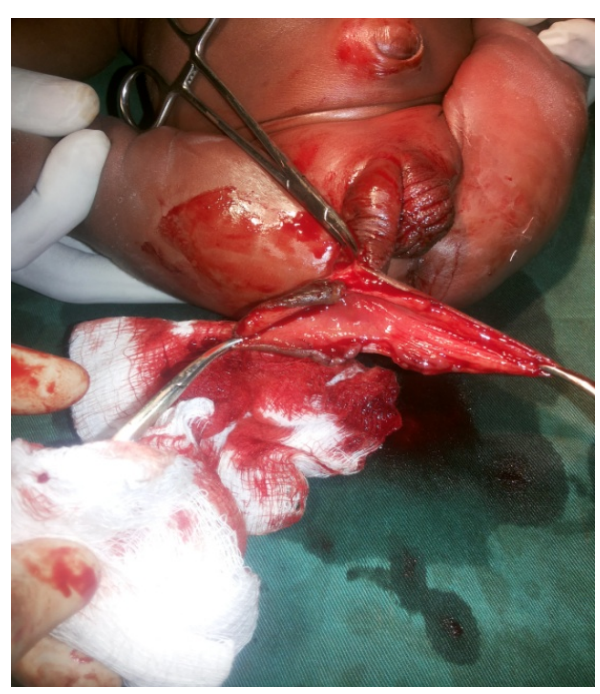

Figure 2. Opened dilated glanular urethra. 


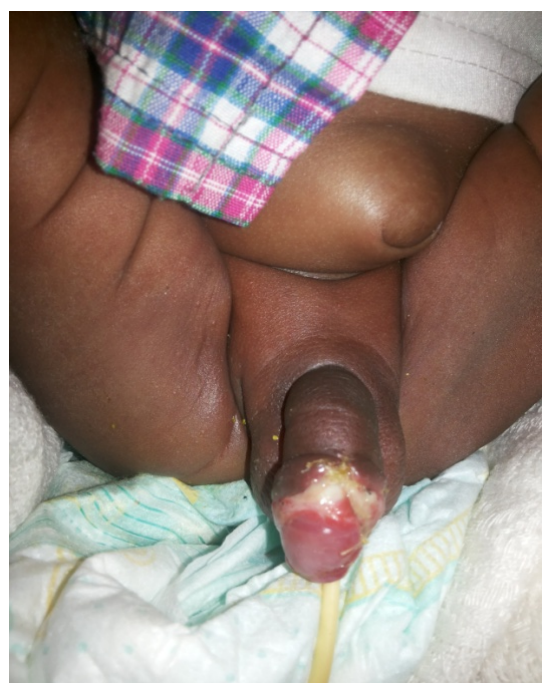

Figure 3. Early post operative outcome.

\section{Discussion}

Anterior urethral valve is an uncommon abnormality whose etiology is uncertain, unlike in the case of posterior urethral valve. Various suggestions as its cause have been forwarded, which include incomplete fusion of the urethral plate, an attempt at urethral duplication and incomplete focal development of the corpus spongiosum [1]. AUV can be located anywhere distal to the membranous urethra [2]. Glanular anterior urethral valve is very rare as in this case report. This might be explained by failure of focal development of the distal part of the corpus spongiosum which differentiates into the glans penis which leads to hypoplasia and dilatation of the glans and glanular urethra leading to pooling of urine and terminal dribbling and recurrent urinary tract infection.

The signs and symptoms of urinary obstruction are the commonest; poor urinary stream and/or terminal dribbling occur in about $40 \%$ of the patients. Serious obstruction concomitantly with hydronephrosis and renal impairment may occur in newborns and infants. Another common sign in distal urethral obstruction due to anterior urethral valve is the bulging of the penile urethra caused by the filling and distension of the urethral diverticulum on straining during urination and sometimes even at rest due to poor emptying of the diverticulum. In severe bladder outflow obstruction, there is concomitant occurrence of bladder distension making it easily palpable [1]-[6]. There are basically two main types of anterior urethral valves distinguished by the presence of absence of diverticulum [7] [8].

The diagnosis of these lesions is mainly clinical, however, maturating cystourethrogramme would reveal the diverticulum while abdominal ultrasonograpy will demonstrate the back pressure effects on the urinary bladder, ureters and kidneys. Blood chemistry will demonstrate presence or absence of renal impairment. Therefore early diagnosis and prompt treatment of these patients will reduce incidence of renal failure.

There are various treatment methods such as open ure-throtomy and excision of the valve, segmental urethrectomy of the valve-bearing area along with a primary end-to-end anastomosis, cold disruption and transurethral resection of the valve. But endoscopic valve ablation by electrocautery has been the procedure of choice [2].

In this case the endoscopic resection diagnosis or resection was not feasible due to lack of appropriate sized cystoscope/resectoscope for our patient's urethra. Vesicostomy is recommended in infants with high grade reflux and poor emptying of the urinary tract. If the urethra is of sufficient caliber and support, transurethral fulguration is recommended. Open urethroplasty is useful in patients with a large urethral diverticulum and thin urethra [8].

Both parents consented to the publication of this case report and I have no complicit of interest or source of funding to declare.

\section{References}

[1] Tucci Jr., S., Franco, P.B., Molina, C.A.F., Suaid, H.J., Cologna, A.J. and Martins, A.C.P. (2003) Anterior Urethral 
Valves. Jornal de Pediatria, 79, 91-94. http://dx.doi.org/10.1590/S0021-75572003000100016

[2] Lassaad, S., Rachida, L., Manel, B.S., Randa, S., Mongi, M., Kais, M., Imed, K., Chahed, J. and Abdellatif, N. (2011) Anterior and Posterior Urethral Valves: A Rare Association. Open Journal of Pediatrics, 1, 34-36. http://dx.doi.org/10.4236/ojped.2011.13009

[3] Paulhac, P., Fourcade, L., Lesaux, N., Alain, J.L. and Colombeau, P. (2003) Anterior Urethral Valves and Diverticula. BJU International, 92, 506-509.

[4] Singh, D.J. and Taneja, R. (2014) Anterior Urethral Valves without Diverticulae: A Report of Two Cases and a Review of the Literature. Congenital Anomalies, 54, 120-122. http://dx.doi.org/10.1111/cga.12032

[5] Kihara, T., Nakai, H., Mori, K.-I., Sato, R., Kitahara, S. and Yasuda, K. (2008) Variety of Congenital Urethral Lesions in Boys with Lower Urinary Tract Symptoms and the Results of Endoscopic Treatment. International Journal of Urology, 15, 235-240. http://dx.doi.org/10.1111/j.1442-2042.2007.01968.x

[6] Chakraborty, J.N. and Mitra, S.K. (2001) Anterior Urethral Valve Resulting from Congenital Urethral Diverticulum in a Child. Journal of Indian Association of Pediatric Surgeons, 6, 146-148.

[7] Cheong, W.Y., Cheng, H.K. and Tan, K.P. (1988) Congenital Anterior Urethral Diverticulum. Singgapore Medicine Journal, 29, 171-175.

[8] Narasimhan, K.L., Choudhary, S.K. and Kaur, B. (2005) Anterior Urethral Valves. Indian Pediatrics, 42, 708-710. 